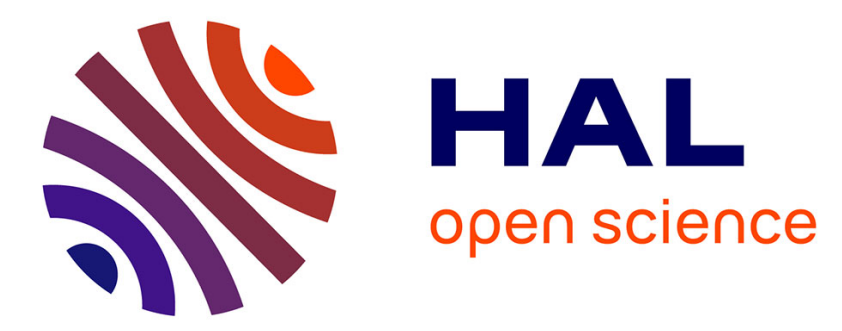

\title{
Topological metastability and oxide ionic conduction in La2-xEuxMo2O9
}

\author{
Gwenaël Corbel, Elodie Chevereau, Stéphanie Kodjikian, P. Lacorre
}

\section{To cite this version:}

Gwenaël Corbel, Elodie Chevereau, Stéphanie Kodjikian, P. Lacorre. Topological metastability and oxide ionic conduction in La2-xEuxMo2O9. Inorganic Chemistry, 2007, 46 (16), pp.6395-6404. 10.1021/ic700876d . hal-00287698

\section{HAL Id: hal-00287698 \\ https://hal.science/hal-00287698}

Submitted on 23 Jul 2019

HAL is a multi-disciplinary open access archive for the deposit and dissemination of scientific research documents, whether they are published or not. The documents may come from teaching and research institutions in France or abroad, or from public or private research centers.
L'archive ouverte pluridisciplinaire HAL, est destinée au dépôt et à la diffusion de documents scientifiques de niveau recherche, publiés ou non, émanant des établissements d'enseignement et de recherche français ou étrangers, des laboratoires publics ou privés. 


\title{
Topological metastability and oxide ionic conduction in $\mathrm{La}_{2-\mathrm{x}} \mathrm{Eu}_{\mathrm{x}} \mathrm{Mo}_{2} \mathrm{O}_{9}$
}

\author{
Gwenaël Corbel,* Elodie Chevereau, Stéphanie Kodjikian, and Philippe Lacorre \\ Laboratoire des Oxydes et Fluorures, UMR CNRS 6010, Université du Maine \\ Avenue Olivier Messiaen, 72085 Le Mans cedex 9, France
}

\begin{abstract}
The effect of partial substitution, up to $\mathrm{x}=0.4$, of La by trivalent $\mathrm{Eu}$ on the phase stability, thermal expansion and transport properties of $\mathrm{La}_{2} \mathrm{Mo}_{2} \mathrm{O}_{9}$ are investigated using X-ray thermodiffraction, differential thermal analysis and complex impedance spectroscopy. At low europium content ( $x \leq 0.1$ ), the $\alpha-\beta$ phase transition is observed at a temperature dependent on the sample shaping (powder, pellet, etc.). At high europium content $(x \geq 0.25)$, the samples remain cubic ( $\beta$ phase), regardless of the shaping. In the intermediate range of europium content $(x=0.15,0.2)$ the phase stability is highly sensitive to the thermal history and the sample shaping, with a double-reversed $\beta$ - $\alpha-\beta$ transition suppressed by the shaping/sintering process. The influence of the amount of europium on the transport mechanisms and parameters is studied in both low- (Arrhenius) and hightemperature (Vogel-Tammann-Fulcher $=\mathrm{VTF}$ ) regimes. If the effect of substitution is rather mild and monotonous within each transport regime and crystallographic phase, an abrupt change in the Arrhenius parameters between the $\alpha$-and $\beta$-type phases is observed.
\end{abstract}

\section{Introduction}

Fast oxide ion conductors are of considerable interest for a range of "clean" electrochemical applications including solid oxide fuel cells, oxygen sensors, and oxygen separation membranes. In this field, Goutenoire and Lacorre discovered, 7 years ago, a novel oxide ion conductor $\mathrm{La}_{2} \mathrm{Mo}_{2} \mathrm{O}_{9} \cdot{ }^{1-2}$ This binary oxide exhibits, above a reversible $\alpha \rightarrow \beta$ structural phase transition, an anionic conductivity higher than that of the conventional $8 \mathrm{~mol} \%$ yttria-stabilized zirconia electrolyte. Most substitutions to $\mathrm{La}$ or $\mathrm{Mo}$ in $\mathrm{La}_{2} \mathrm{Mo}_{2} \mathrm{O}_{9}$ stabilize, above a certain content, the high-T anionically disordered cubic $\beta$-form at room temperature. ${ }^{3-5}$ Our recent investigations were focused on the relationship between crystal structure, thermal expansion, and electrical properties. ${ }^{6-7}$

* To whom correspondence should be addressed. Phone: $+33(0) 243$ 8326 48. Fax: +33 (0)2 $43 \quad 83 \quad 35$ 06. E-mail: gwenael.corbel@ univ-lemans.fr

(1) Lacorre, P.; Goutenoire, F.; Bohnke, O.; Retoux, R.; Laligant, Y. Nature 2000, 404, 856.

(2) Goutenoire, F.; Isnard, O.; Retoux, R.; Lacorre, P. Chem. Mater. 2000, 12, 2575.

(3) Goutenoire, F.; Isnard, O.; Suard, E.; Bohnké, O.; Laligant, Y.; Retoux, R.; Lacorre, P. J. Mater. Chem. 2001, 11, 119.

(4) Georges, S.; Goutenoire, F.; Altorfer, F.; Sheptyakov, D.; Fauth, F.; Suard, E.; Lacorre, P. Solid State Ionics 2003, 161, 231.

(5) Corbel, G.; Laligant, Y.; Goutenoire, F.; Suard, E.; Lacorre, P. Chem. Mater. 2005, 17, 4678.

(6) Georges, S.; Bohnké, O.; Goutenoire, F.; Laligant, Y.; Fouletier, J.; Lacorre, P. Solid State Ionics 2006, 177, 1715.
The isovalent substitution of lanthanum by europium in $\mathrm{La}_{2} \mathrm{Mo}_{2} \mathrm{O}_{9}$ was first explored, up to a content of $x=0.25$, by Marrero-López et al. ${ }^{8}$ These nanocrystalline oxides were elaborated from freeze-dried precursors, and the electrical conductivity was measured. These authors have found that the substitution of a fraction $(x=0.05)$ of lanthanum for europium involves an increase by an order of magnitude of the ionic conductivity relative to $\mathrm{La}_{2} \mathrm{Mo}_{2} \mathrm{O}_{9}$. Moreover, the conductivity curve of $\mathrm{La}_{1.9} \mathrm{Eu}_{0.1} \mathrm{Mo}_{2} \mathrm{O}_{9}$ looks like the curve of a cubic member, whereas the DTA thermogram clearly shows an endothermic peak ascribed to the $\alpha \rightarrow \beta$ phase transition. This difference in the behavior of the raw powder and sintered ceramic was not pointed out neither discussed by Marrero-López et al. in their paper. In the present paper, this solid solution was re-examined to obtain a deeper insight into the influence of europium on the crystal structure, thermal stability, and electrical properties.

\section{Experimental Section}

Powder Synthesis. One gram polycrystalline samples of $\mathrm{La}_{2-} \mathrm{Eu}_{x} \mathrm{Mo}_{2} \mathrm{O}_{9}(x=0.05,0.1,0.15,0.2,0.25,0.3,0.4)$ were prepared by conventional solid-state reaction. Prior to use, $\mathrm{La}_{2} \mathrm{O}_{3}$

(7) Lacorre, P.; Selmi, A.; Corbel, G.; Boulard, B. Inorg. Chem. 2006, 45,627 .

(8) Marrero-López, D.; Núñez, P.; Abril, M.; Lavín, V.; RodríguezMendoza, U. R.; Rodríguez, V. D. J. Non-Cryst. Solids 2004, 345346, 377. 
and $\mathrm{Eu}_{2} \mathrm{O}_{3}$ were calcinated in air for $12 \mathrm{~h}$ at $1000{ }^{\circ} \mathrm{C}$ to remove adsorbed water and carbon dioxide. The stoichiometric mixture of $\mathrm{La}_{2} \mathrm{O}_{3}, \mathrm{Eu}_{2} \mathrm{O}_{3}$, and $\mathrm{MoO}_{3}$ was first heated in an alumina crucible at $500{ }^{\circ} \mathrm{C}$ for $12 \mathrm{~h}$ (heating and cooling rates of $2{ }^{\circ} \mathrm{C} / \mathrm{min}$ ). Then, several annealings with regrindings in acetone in between were necessary to obtain a pure single phase. The final firing temperatures were 1000 and $1050{ }^{\circ} \mathrm{C}$ (heating and cooling rates of $5{ }^{\circ} \mathrm{C} / \mathrm{min}$ ) for europium content lower and higher than $x=0.20$, respectively.

Europium Valence Determination. To determine the valence of europium cation in the $\mathrm{La}_{2-x} \mathrm{Eu}_{x} \mathrm{Mo}_{2} \mathrm{O}_{9}$ series, all compositions were excited by a short-wavelength $254 \mathrm{~nm}$ ultraviolet lamp at room temperature. All substituted samples exhibit an intense red emission characteristic of trivalent europium ion ${ }^{9}$ (Figure S1 in the Supporting Information). The isovalent nature of the substitution is confirmed: the balance between oxygen and vacancy in the structure is kept constant.

Structural Characterization. After completion, X-ray powder diffraction patterns were recorded at room temperature on a $\theta / \theta$ Bragg-Brentano Philips X'pert MPD PRO diffractometer

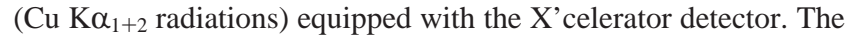
powder was dusted through a $63 \mu \mathrm{m}$ sieve on a glass holder. Diffractograms were collected during $400 \mathrm{~min}$ in the $\left[5-130^{\circ}\right]$ scattering angle range, with a $0.0084^{\circ}$ step. The program FullProf ${ }^{10}$ was used for Le Bail's fits.

Thermodiffractograms were collected on the same diffractometer equipped with an HTK 1200 Anton Paar chamber using an $\mathrm{Al}_{2} \mathrm{O}_{3}$ sample holder cup. Diffractograms were recorded under air flow from room temperature (RT) to $950{ }^{\circ} \mathrm{C}$ (heating rate of $10^{\circ} \mathrm{C} / \mathrm{min}$, temperature stabilization for $20 \mathrm{~min}$ with temperature correction after calibration). ${ }^{11} \mathrm{~A}\left[9-130^{\circ}\right]$ or $\left[15-130^{\circ}\right]$ scattering angle range with a $0.0084^{\circ}$ step was used for europium contents of lower or higher than $x=0.20$, respectively. The thermal evolution of the (231) diffraction line of $x=0.15$ and 0.2 pellet samples was recorded from $\mathrm{RT}$ to $950{ }^{\circ} \mathrm{C}$ in the $\left[46-48.75^{\circ}\right]$ scattering angle range (counting time of $11 \mathrm{~min}$ ).

The electron microscopy study was performed with a $200 \mathrm{kV}$ JEOL 2010 TEM equipped with a side entry $\pm 30^{\circ}$ double-tilt specimen holder. The raw powder was ground in absolute ethanol, and one droplet was deposited on a carbon-coated holey film supported by a copper grid. This microscope is coupled with a KEVEX energy dispersive spectroscopy analyzer.

Thermal Analysis. Thermal analyses were performed on raw powders with a TGA/DTA Q600 SDT TA Instuments apparatus (Pt crucibles, $\mathrm{Al}_{2} \mathrm{O}_{3}$ as a reference) under air flow $(100 \mathrm{~mL} / \mathrm{min})$. For $x \leq 0.20$, thermograms were collected on $\sim 20 \mathrm{mg}$ samples in the $\mathrm{RT}-1000{ }^{\circ} \mathrm{C}$ range (heating/cooling rate of $10{ }^{\circ} \mathrm{C} / \mathrm{min}$ ). For $x$ $>0.20$, DTA measurements were carried out on $\sim 50 \mathrm{mg}$ samples with 3 heating/cooling cycles from RT to $800{ }^{\circ} \mathrm{C}\left(20^{\circ} \mathrm{C} / \mathrm{min}\right)$.

Transport Properties. Pellets with high relative density ( $>95 \%$ of theoretical density) were obtained from fine grain powders $(\sim 1 \mu \mathrm{m})$. Grain size reduction was performed by ballmilling using a FRITSCH planetary micromill pulverizette 7 apparatus. Typically, $900 \mathrm{mg}$ of raw powder were placed into a 45 $\mathrm{cm}^{3}$ agate bowl with six $12 \mathrm{~mm}$ diameter agate balls (ball-to-powder mass ratio of around 16:1) and covered with ethanol. Milling conditions were four alternations of 15 min milling sequences at $700 \mathrm{rpm}$ with $15 \mathrm{~min}$ pause in between. Milled powders were then

(9) (a) Neeraj, S.; Kijima, N.; Cheetham, A. K. Solid State Commun. 2004, 131, 65. (b) Neeraj, S.; Kijima, N.; Cheetham, A. K. Chem. Phys. Lett. 2004, 387, 2. (c) Grobelna, B.; Lipowska, B.; Klonkowski, A. M. J. Alloys Compd. 2006, 419, 191.

(10) Rodriguez-Carvajal, J. Physica (Amsterdam) 1993, 192B, 55.

(11) Corbel, G.; Mestiri, S.; Lacorre, P. Solid State Sci. 2005, 7, 1216.

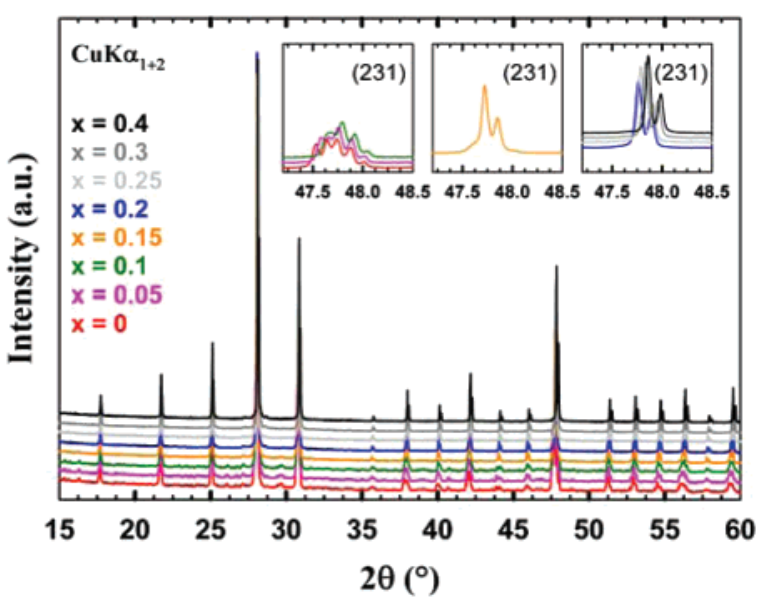

Figure 1. RT X-ray diffraction patterns of $\mathrm{La}_{2-x} \mathrm{Eu}_{x} \mathrm{Mo}_{2} \mathrm{O}_{9}$ raw powder samples. The insets show the disappearance of the monoclinic splitting upon europium substitution through the evolution of the (231) pseudocubic lines.

dried slowly at $100{ }^{\circ} \mathrm{C}$. Polyvinyl alcohol $\left(\left(\mathrm{C}_{2} \mathrm{H}_{4} \mathrm{O}\right)_{n}\right.$ in water solution) was used as bending agent. The compaction into pellets ( $5 \mathrm{~mm}$ in diameter and $3-5 \mathrm{~mm}$ in thickness) was achieved by uniaxial hydraulic pressing (500 MPa load), followed by a final $\mathrm{RT}$ isostatic pressing $(550-580 \mathrm{MPa})$ in a Top Industrie apparatus. The axial shrinkage was continuously recorded up to the synthesis temperature (to prevent decomposition) with a vertical dilatometer SETARAM TMA Setsys Evolution $16(20 \mathrm{~mL} / \mathrm{min}$ air flow, heating/cooling rate of $5{ }^{\circ} \mathrm{C} / \mathrm{min}$ ). After the sample was sintered, the phase purity was checked on the pellet by X-ray diffraction.

Thin Pt film electrodes were deposited by magnetron sputtering on both flat faces of the sintered pellets. Two-probe electrical conductivity measurements were carried out using a Solartron 1260 frequency response analyzer connected to a Solartron 1296 dielectric interface over the $10 \mathrm{MHz}$ to $0.05 \mathrm{~Hz}$ range (ac voltage of $50 \mathrm{mV}$, 40 points/decade). Complex impedance spectra were recorded under dry air flow every $25^{\circ} \mathrm{C}$ ( $35 \mathrm{~min}$ thermal equilibration) over the temperature range of $300-725^{\circ} \mathrm{C}$ for all compositions, except those containing an europium content of $x \leq 0.25$. For these latter compositions, additional spectra were collected every $5{ }^{\circ} \mathrm{C}$ in the intermediate range of $550-600{ }^{\circ} \mathrm{C}$. Impedance diagrams plotted in the Nyquist complex plane present a spike at the low-frequency side characteristic of the electrode polarization phenomenon. This spike was fitted with a Warburg element with the Z-view $2.8 \mathrm{~d}$ software. ${ }^{12}$ In the $300-475{ }^{\circ} \mathrm{C}$ range, high frequency and lower frequency semicircles were observed and least-squares fitted with a series combination of two (R//CPE) elements. On the basis of the values of capacitance $\left(\sim 1.10^{-11} \mathrm{~F}\right)$, the former arc was assigned to the bulk response, while the latter $\left(\sim 4.10^{-9} \mathrm{~F}\right)$ was associated to the grain boundaries contribution. Above $475{ }^{\circ} \mathrm{C}$, only one semicircle was distinguished.

\section{Results and Discussion}

Phase Existence Domain and Structural Evolution with Europium Content. The room-temperature X-ray diffraction patterns of $\mathrm{La}_{1.95} \mathrm{Eu}_{0.05} \mathrm{Mo}_{2} \mathrm{O}_{9}$ and $\mathrm{La}_{1.9} \mathrm{Eu}_{0.1} \mathrm{Mo}_{2} \mathrm{O}_{9}$ clearly exhibit the peak splitting characteristic of the slight monoclinic distortion and the $2 \times 3 \times 4$ superstructure peaks at low $2 \theta$ scattering angle relative to the $\beta-\mathrm{La}_{2} \mathrm{Mo}_{2} \mathrm{O}_{9}$ form (Figure 1). ${ }^{2}$ This was confirmed by DT analysis (Figure 2):

(12) Z-View, 2.8d; Scribner Associates Inc: Southern Pines, NC. 


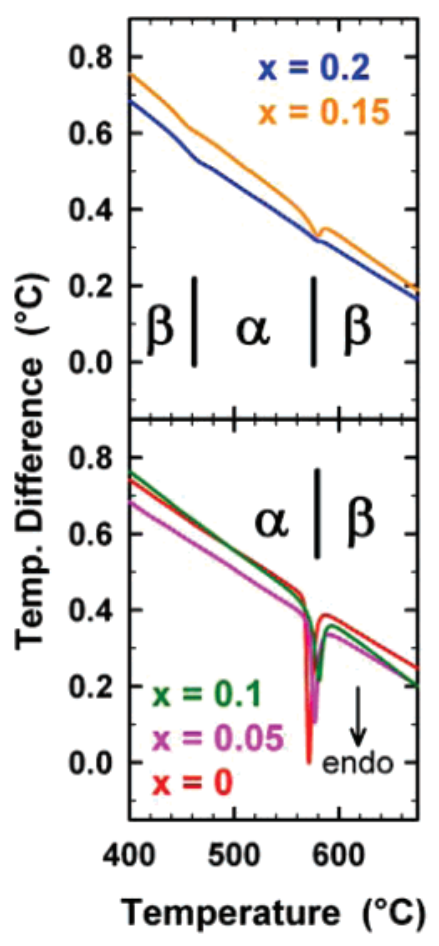

Figure 2. DTA thermograms upon heating $\left(10{ }^{\circ} \mathrm{C} / \mathrm{min}\right)$ in air of $\mathrm{La}_{2-x} \mathrm{Eu}_{x} \mathrm{Mo}_{2} \mathrm{O}_{9}$ raw powder samples.

Table 1. First-Order Transition Temperatures of Raw Powder of $\mathrm{La}_{2-x} \mathrm{Eu}_{x} \mathrm{Mo}_{2} \mathrm{O}_{9}$ Determined by DTA in Air

\begin{tabular}{lccccc}
\hline & \multicolumn{2}{c}{$\begin{array}{c}\alpha \rightarrow \beta \text { transition } \\
\text { temperature }\left({ }^{\circ} \mathrm{C}\right)\end{array}$} & & \multicolumn{2}{c}{$\begin{array}{l}\beta \rightarrow \alpha \text { transition } \\
\text { temperature }\left({ }^{\circ} \mathrm{C}\right)\end{array}$} \\
\cline { 2 - 3 } \cline { 5 - 6 } \multicolumn{1}{c}{ onset } & peak max & & onset & peak max \\
\hline 0 & 568 & 571 & & 558 & 548 \\
0.05 & 572 & 577 & & 542 & 534 \\
0.1 & 573 & 581 & & 537 & 503 \\
0.15 & 565 & 580 & & $a$ & $a$ \\
0.2 & 562 & 580 & & $a$ & $a$
\end{tabular}

${ }^{a}$ Too diffuse to be detected

an endothermic peak upon heating up, associated to the reversible $\alpha \rightarrow \beta$ structural phase transition, was seen around $570-580{ }^{\circ} \mathrm{C}$. With increasing europium content, a slight shift of this transition toward higher temperatures is observed (Table 1). The reduction in intensity of the thermal peak upon substitution is consistent with the slightly smaller monoclinic splitting of the pseudocubic (231) diffraction line. The broadening of the peak (increase of the difference between the temperature at the onset point and at the peak maximum in Table 1) reflects the increase of cationic disorder introduced by the europium substitution. Above an europium content of $x=0.25$, the stabilization of the cubic $\beta$-phase at room temperature occurs. These results are in agreement with the investigations of Marrero-López et al. ${ }^{8}$ undertaken on samples elaborated from freeze-dried precursors.

For two intermediate compositions, $x=0.15$ and $x=0.2$, Figure 1 shows that the (231) cubic reflections are widened and less intense than those of the $x=0.25,0.3$, and 0.4 samples. Furthermore, a weaker peak at lower scattering angle (not attributed to the asymmetry effect) was observed for the $\mathrm{La}_{1.85} \mathrm{Eu}_{0.15} \mathrm{Mo}_{2} \mathrm{O}_{9}$ sample (see the arrow in Figure 1 ). DTA thermogram collected on the $x=0.15$ sample upon

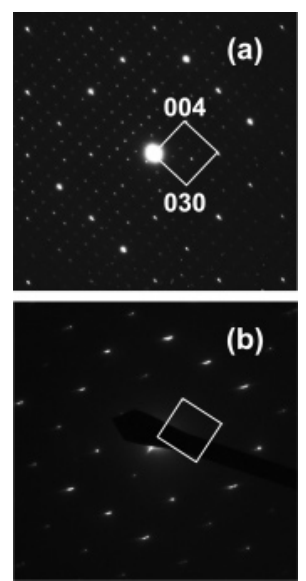

Figure 3. Typical SAED patterns of $\alpha-\mathrm{La}_{1.85} \mathrm{Eu}_{0.15} \mathrm{Mo}_{2} \mathrm{O}_{9}$ along [100] (a) and of the $\beta$-type phase (b).

heating reveals the existence of a broad endothermic peak around $580{ }^{\circ} \mathrm{C}$ at the first-order $\alpha / \beta$ transition, whereas a subtle break is detected for the $x=0.15$ and $x=0.2$ samples at lower temperatures. These measurements carried out on two different as-prepared samples were reproducible. For both samples, the occurrence of these transitions evoked the coexistence of the two polymorphs $(\alpha+\beta)$. This assumption would explain the presence of (231) overlapping peaks belonging to $\alpha$ and $\beta$ forms noted for the $\mathrm{La}_{1.85} \mathrm{Eu}_{0.15} \mathrm{Mo}_{2} \mathrm{O}_{9}$ sample. The ratio (low-temperature form $\alpha /$ high-temperature form $\beta$ ) tends to decrease as $x$ increases because this overlapping is not detected for $x=0.2$.

To confirm the biphasic feature of the $\mathrm{La}_{1.85} \mathrm{Eu}_{0.15} \mathrm{Mo}_{2} \mathrm{O}_{9}$ sample, room-temperature electron diffraction patterns were collected on 11 different crystallites. At first, the elemental composition of each crystallite was checked by energy dispersive X-ray spectroscopy analysis. No significant variation in La and Mo content was detected between crystallites. For 5 of the 11 crystallites, the presence of the monoclinic superstructure relative to the cubic $\beta$ phase was confirmed. As shown in the selected area electron diffraction pattern along [100] (Figure 3a), the tripling and quadrupling of cell parameter characteristic of the $\times 2 \times 3 \times 4$ superstructure of $\alpha-\mathrm{La}_{2} \mathrm{Mo}_{2} \mathrm{O}_{9}$ is clearly found. For the 6 latter crystallites, all SAED patterns exhibit elongated Bragg reflections that can be all indexed onto a cubic cell with a parameter of $\sim 7.14 \AA$. It must be mentioned that the zone axis orientation of ED patterns cannot be determined because of the cubic symmetry. Note that in Figure $3 b$, the diffuse scattering is oriented along one diagonal of the basal plane. This implies that the statical disorder is limited to layers perpendicular to [110], [101], or [011] direction. Unfortunately, the tilting angle of the specimen holder is limited to $\pm 30^{\circ}$ making a reconstruction of the total reciprocal lattice impossible. However, this experiment has shown that the coexistence of the two polymorphs $(\alpha+\beta)$ within the sample of $\mathrm{La}_{1.85^{-}}$ $\mathrm{Eu}_{0.15} \mathrm{Mo}_{2} \mathrm{O}_{9}$ is not involved by any gradient of composition.

As it will be demonstrated in Section 3.3 thanks to in situ high-temperature X-ray diffraction, the presence of the subtle break around $450{ }^{\circ} \mathrm{C}$ in the DT thermograms of both the $\mathrm{La}_{1.85} \mathrm{Eu}_{0.15} \mathrm{Mo}_{2} \mathrm{O}_{9}$ and $\mathrm{La}_{1.8} \mathrm{Eu}_{0.2} \mathrm{Mo}_{2} \mathrm{O}_{9}$ samples originates 


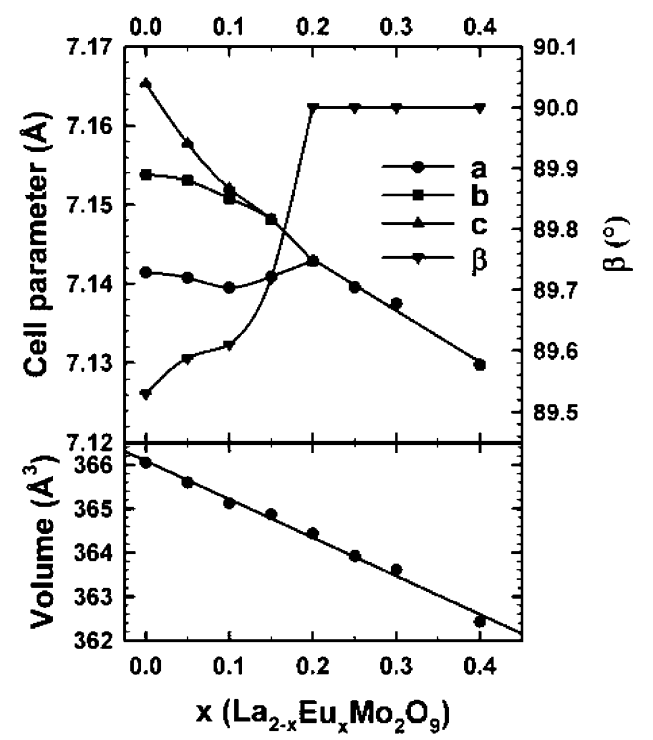

Figure 4. Variations of the unit cell parameters and volume of $\mathrm{La}_{2-x} \mathrm{Eu}_{x} \mathrm{Mo}_{2} \mathrm{O}_{9}$ with $\mathrm{x}$. Error bars are approximately the size of the data points.

from the metastability of $\beta$-phase, which transforms back to stable $\alpha$ phase.

Unit cell parameters were obtained by the pattern-matching fit of diffractograms either in a single monoclinic subcell (space group $P 2_{1}$ (No. 4)) for $x \leq 0.15$ or in a cubic cell (space group $P 2{ }_{1} 3$ (No. 198)) for $x \geq 0.2$. Along the series, the linear reduction of the unit cell volume with increasing the europium content $x$ (usual Vegard's law, Figure 4) reflects that trivalent europium cation (ionic radii $=0.947$ $(\mathrm{CN}=6), 1.12 \AA(\mathrm{CN}=9))^{13}$ is much smaller than lanthanum ion (ionic radii $=1.032(\mathrm{CN}=6), 1.216 \AA(\mathrm{CN}$ $=9)) \cdot{ }^{13}$ The formation of a partial solid solution is then established in the whole composition range, all the studied samples being pure. Moreover, this work shows that the composition range explored by Marrero-López et al. ${ }^{8}$ can be extended at least up to an europium concentration of $x=$ 0.4. This is in good agreement with previous studies carried out on trivalent samarium- ${ }^{14}$ or gadolinium-substituted $^{4}$ LAMOX samples.

Sintering Process. At first, the thermal instability of ball-milled powders was determined from TG analysis. A continuous weight loss takes place above $1100{ }^{\circ} \mathrm{C}$ before the lanthanum molybdate starts to melt. It must be noted that the abrasion of agate balls during milling can introduce a weak $\mathrm{SiO}_{2}$ contamination. When a sintering temperature of $1075{ }^{\circ} \mathrm{C}$ was applied (higher than the synthesis temperature of raw powders, i.e., $1000-1050{ }^{\circ} \mathrm{C}$ ), a clear increase of the bulk resistance above $560{ }^{\circ} \mathrm{C}$ was observed by complex impedance spectroscopy. This decrease of the bulk conductivity cannot be attributed to oxygen losses involving the partial reduction of molybdenum cation (mixed valence) because the resulting electronic contribution would increase

(13) Shannon, R. D. Acta Crystallogr. 1976, 32, 751.

(14) Yang, J.; Gu, Z.; Wen, Z.; Yan, D. Solid State Ionics 2005, 176, 523. the total conductivity. ${ }^{15}$ Although consecutive X-ray diffraction did not reveal any extra diffraction peaks, the presence of an insulating phase at the grain boundaries of the pellet (either from LAMOX decomposition or reaction with silica contaminant) cannot be ruled out.

A method to sinter europium-substituted samples, while preventing any decomposition or any formation of an insulating phase, was to apply an isothermal treatment for 3 $\mathrm{h}$ at the final synthesis temperature of corresponding raw powders (Table 2). All results reported hereafter were obtained on ceramic samples sintered under these conditions. No increase of the bulk resistance was observed by complex impedance spectroscopy as shown in Figure 6. It is worth noting that the conductivity curve that we reported for $\mathrm{La}_{1.75^{-}}$ $\mathrm{Eu}_{0.25} \mathrm{Mo}_{2} \mathrm{O}_{9}$ is identical to the curve presented by MarreroLópez et al. This result is important because these authors have elaborated at $500{ }^{\circ} \mathrm{C}$ the nanocrystalline powder used to prepare the pellet sintered at $950{ }^{\circ} \mathrm{C}$. In our study, the possible $\mathrm{SiO}_{2}$ contamination introduced by the ball milling stage and the possible molybdenum oxide losses during the sintering were then considered as negligible. Furthermore, despite the reduction of the sintering temperature to the synthesis temperature, all sintered pellets exhibit relative densities $\rho$ higher than $96 \%$ (Table 2). This can be explained by the fact that an isotherm at lower temperature slows down the densification and minimizes the separation of pores from the boundaries (trapping of pores inside large grains when the grain growth is faster than the pore motion). ${ }^{16} \mathrm{X}$-ray diffraction patterns show that all sintered pellets are pure. The linear shrinkage, $\Delta l / l_{0}$, values as a function of the temperature for several compositions are shown in the Supporting Information.

Thermal Stability and Charge Transport versus Composition. A previous study showed correlations between oxide-ion conduction increase and thermal expansion in the LAMOX family. ${ }^{7}$ The thermal stability of all members of the solid solution $\mathrm{La}_{2-} \mathrm{Eu}_{x} \mathrm{Mo}_{2} \mathrm{O}_{9}$ was investigated by using in situ high-temperature $\mathrm{X}$-ray powder diffraction performed in air. From the Le Bail's fit of high-temperature patterns, the thermal evolution of the single-cell volume is determined and given in Figure 5. In the linear regimes, data were fitted with a linear regression to deduce the average thermal expansion coefficient reported in Table 3 . The relative thermal expansion $\Delta l / l_{0}$ curves of air-sintered ceramic pellets of $\mathrm{La}_{2-x} \mathrm{Eu}_{x} \mathrm{Mo}_{2} \mathrm{O}_{9}$ are reported in Figure $\mathrm{S} 3$ of the Supporting Information. Finally, Figure 6 shows the dependence of their total ionic conductivity in the temperature range of $300-725^{\circ} \mathrm{C}$. Data relative to pure $\mathrm{La}_{2} \mathrm{Mo}_{2} \mathrm{O}_{9}$ are also added in Figures 5, S3, and 6, for reference. We will first examine low Eu content samples $(x=0.05,0.1)$, then the high content

(15) (a) Tarancón, A.; Norby, T.; Dezanneau, G.; Morata, A.; Peiró, F.; Morante, J. R. Electrochem. Solid State Lett. 2004, 7 (10), A373. (b) Marozau, I. P.; Marrero-López, D.; Shaula, A. L.; Kharton, V. V.; Tsipis, E. V.; Núñez, P.; Frade, J. R. Electrochim. Acta 2004, 49 3517. (c) Pinet, P.; Fouletier, J.; Georges, S. Mater. Res. Bull. 2007, 42,935

(16) Upadhyaya, G. S. In Sintered metallic and ceramic materials, Preparation, Properties and Applications; John Wiley \& Sons Ltd: Oxford, U.K., 2000. 


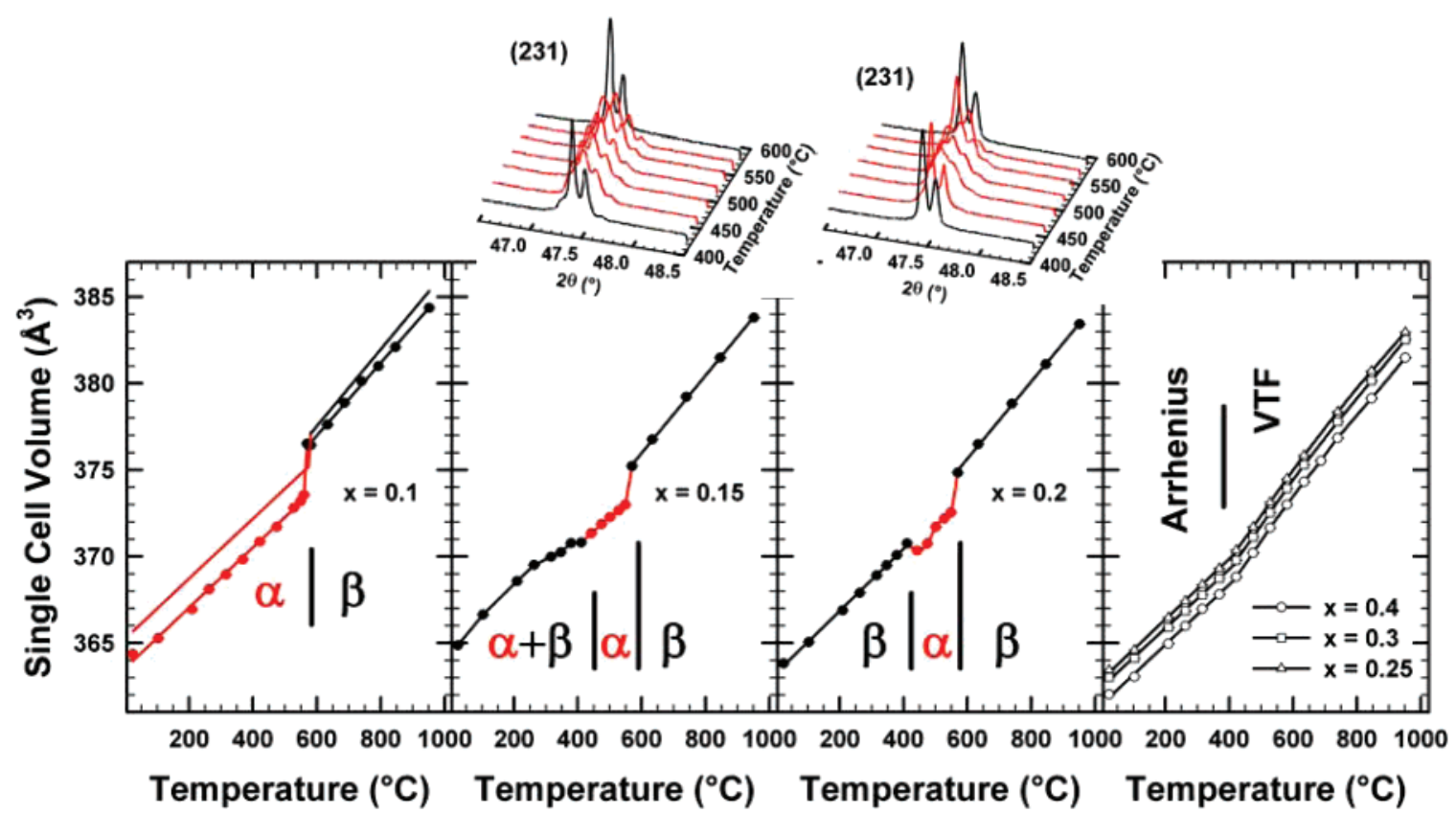

Figure 5. Temperature dependencies of the single cell volume of $\mathrm{La}_{2-x} \mathrm{Eu}_{x} \mathrm{Mo}_{2} \mathrm{O}_{9}$ raw powder samples determined from temperature-controlled $\mathrm{X}$-ray diffraction data. To compare with $\mathrm{La}_{1 .} \mathrm{Eu}_{0.1} \mathrm{Mo}_{2} \mathrm{O}_{9}$, the thermal volume expansion of $\mathrm{La}_{2} \mathrm{Mo}_{2} \mathrm{O}_{9}$ is added as red $(\alpha$-form) and black ( $\beta$-form) solid lines for reference. The insets display the thermal evolution of the (231) pseudocubic reflection line for $\mathrm{La}_{1.85} \mathrm{Eu}_{0.15} \mathrm{Mo}_{2} \mathrm{O}_{9}$ and $\mathrm{La}_{1.8} \mathrm{Eu}_{0.2} \mathrm{Mo}_{2} \mathrm{O}_{9}$.

Table 2. Sintering Conditions and Relative Densities of $\mathrm{La}_{2-x} \mathrm{Eu}_{x} \mathrm{Mo}_{2} \mathrm{O}_{9}$ Pellets

\begin{tabular}{lcc}
\hline \multicolumn{1}{c}{$x$} & $\begin{array}{c}\text { sintering } \\
\text { temperature }\end{array}$ & $\begin{array}{c}\text { relative density } \\
\rho(\%)\end{array}$ \\
\hline 0 & $1000^{\circ} \mathrm{C}$ & $96(1)$ \\
0.05 & $1000^{\circ} \mathrm{C}$ & $96(1)$ \\
0.1 & $1000^{\circ} \mathrm{C}$ & $97(1)$ \\
0.15 & $1000^{\circ} \mathrm{C}$ & $97(1)$ \\
0.2 & $1000^{\circ} \mathrm{C}$ & $98(1)$ \\
0.25 & $1025^{\circ} \mathrm{C}$ & $98(1)$ \\
0.3 & $1050^{\circ} \mathrm{C}$ & $99(1)$ \\
0.4 & $1050^{\circ} \mathrm{C}$ & $99(1)$
\end{tabular}

ones $(x=0.25-0.4)$, and end with those in the intermediate range $(x=0.15,0.2)$.

$\mathrm{La}_{1.95} \mathrm{Eu}_{0.05} \mathrm{Mo}_{2} \mathrm{O}_{9}$ and $\mathrm{La}_{1.9} \mathrm{Eu}_{0.1} \mathrm{Mo}_{2} \mathrm{O}_{9}$. The $\mathrm{La}_{1.9^{-}}$ $\mathrm{Eu}_{0.1} \mathrm{Mo}_{2} \mathrm{O}_{9}$ powder sample displays a $0.8 \%$ abrupt cell volume expansion, larger than the one observed for pure lanthanum molybdate $(0.53 \%)$, at the structural $\alpha / \beta$ phase transition (Figure 5). This jump in the thermal expansion is lowered to $0.2 \%$ when the samples of $\mathrm{La}_{2} \mathrm{Mo}_{2} \mathrm{O}_{9}, \mathrm{La}_{1.95} \mathrm{Eu}_{0.05^{-}}$ $\mathrm{Mo}_{2} \mathrm{O}_{9}$, and $\mathrm{La}_{1.9} \mathrm{Eu}_{0.1} \mathrm{Mo}_{2} \mathrm{O}_{9}$ are shaped into the form of a dense pellet (Figure S3). The difference between the volume expansion measured on a pellet by dilatometry and on a powder by XRD can originate from the difference in measurement techniques, but it might also be a sign of the effect of sample shaping on the equilibrium of point defects. In the low-temperature range, the average thermal expansion coefficient of $\alpha-\mathrm{La}_{1.9} \mathrm{Eu}_{0.1} \mathrm{Mo}_{2} \mathrm{O}_{9}$ and $\alpha-\mathrm{La}_{2} \mathrm{Mo}_{2} \mathrm{O}_{9}$ are almost equal (Table 3 ). This was confirmed by dilatometry (Figure S3) because the $\Delta l / l_{0}$ curves are perfectly superimposed below $580{ }^{\circ} \mathrm{C}$ regardless of the europium content considered. Above $580{ }^{\circ} \mathrm{C}$, slight decreases of the $\alpha$ coefficient (Table 3 ) and of the relative expansion $\Delta l / l_{0}$ (Figure S3) are noted for $\beta$ - $\mathrm{La}_{1.9} \mathrm{Eu}_{0.1} \mathrm{Mo}_{2} \mathrm{O}_{9}$.

The thermal dependencies of the total conductivity of the $\mathrm{La}_{1.95} \mathrm{Eu}_{0.05} \mathrm{Mo}_{2} \mathrm{O}_{9}$ and $\mathrm{La}_{1.9} \mathrm{Eu}_{0.1} \mathrm{Mo}_{2} \mathrm{O}_{9}$ samples are consistent with temperature-controlled diffraction data. The conductivity jump of about 1 order of magnitude, when the first order $\alpha / \beta$ phase transition takes place in $\mathrm{La}_{2} \mathrm{Mo}_{2} \mathrm{O}_{9}$, did not change significantly with the europium concentration. However, when $x$ increases, the transition temperature $T_{\alpha / \beta}$ is progressively shifted toward the low-temperature region (Figure 6). Correlatively, the narrow peak in plots of the first derivative of the conduction with respect to temperature (Figure 6), associated to the first-order transition of $\mathrm{La}_{2} \mathrm{Mo}_{2} \mathrm{O}_{9}$, is broadened and less intense as the europium content increases. Note that an opposite evolution of $T_{\alpha / \beta}$ has been shown on powder samples by differential thermal analysis. This difference could arise from the dynamic character of DTA measurement or from sample shaping. In the temperature range of $300-500{ }^{\circ} \mathrm{C}$, conductivity curves have been fitted with an Arrhenius-type law $\sigma T=\sigma_{0} \exp \left(-E_{\mathrm{a}} / R T\right)$ (thermally activated anionic mobility) with an activation energy $E_{\mathrm{a}}$ of $1.1 \mathrm{eV}$ regardless of the value of $x$ (Figure $7 \mathrm{a}$ ). In the hightemperature region, the bulk conductivity is not enhanced significantly through $\mathrm{La}^{3+} / \mathrm{Eu}^{3+}$ substitution.

It must be underlined that this observation is not consistent with results published on this series by Marrero-López et al. ${ }^{8}$ These authors have measured an increase by an order of magnitude, in the whole temperature range explored, of the ionic conductivity of $\mathrm{La}_{2} \mathrm{Mo}_{2} \mathrm{O}_{9}$ when a fraction, $x=0.05$, of lanthanum is substituted with europium. However, the authors attributed this increase of conductivity to the sample microstructure because the sintered pellet of $\mathrm{La}_{1.95} \mathrm{Eu}_{0.05^{-}}$ $\mathrm{Mo}_{2} \mathrm{O}_{9}$ exhibits the higher relative density (98\%) among all substituted samples. Note that, in our series, all relative densities are in the range of 96-99\% (Table 2). Moreover, another discrepancy with the Marrero-López et al. results concerns the $x=0.1$ europium sample. The conductivity curve of $\mathrm{La}_{1.9} \mathrm{Eu}_{0.1} \mathrm{Mo}_{2} \mathrm{O}_{9}$ they reported looks like the curve 

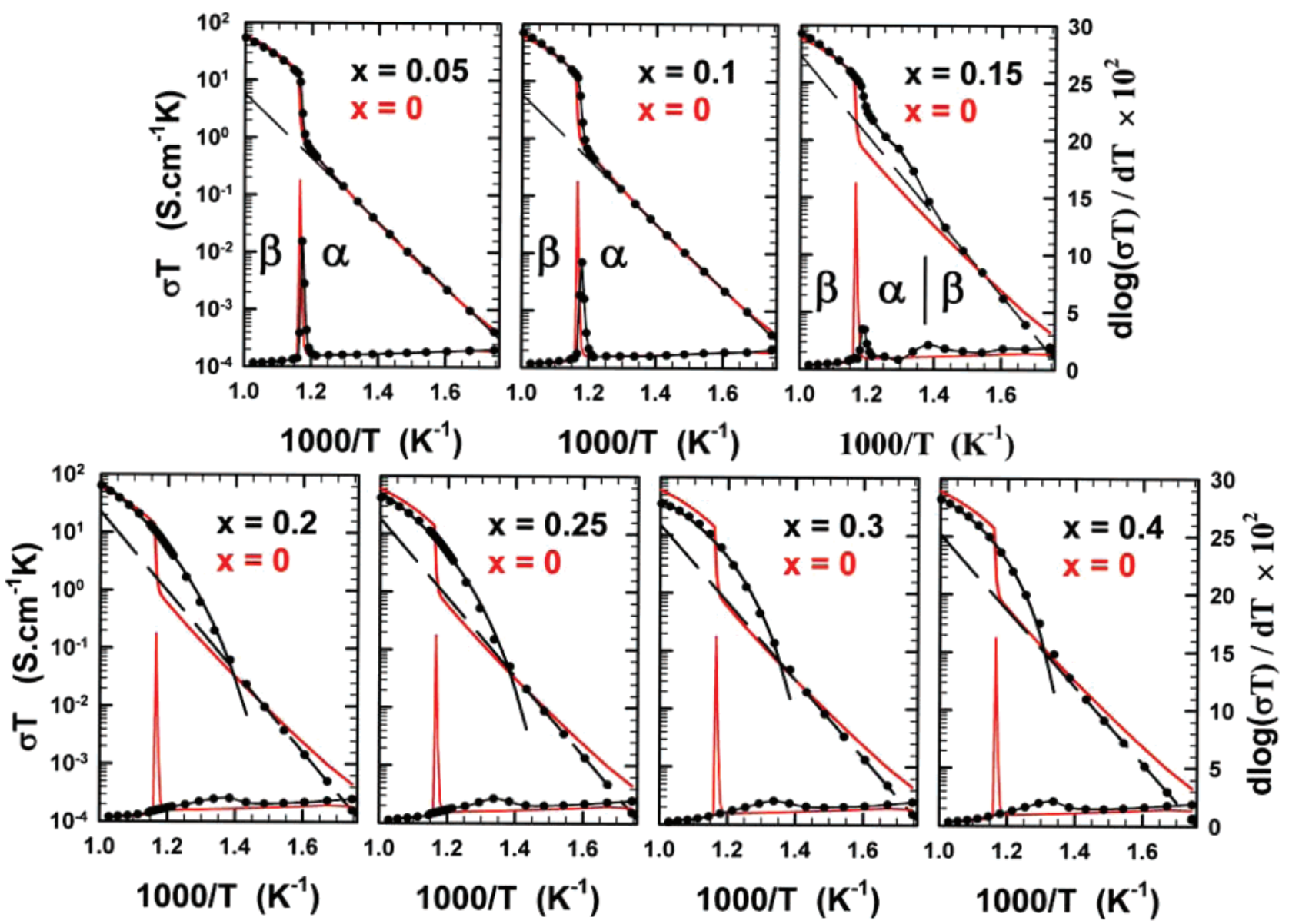

Figure 6. Temperature dependencies of the electrical conductivity measured in air on dense ceramics of the $\mathrm{La}_{2-x} \mathrm{Eu}_{x} \mathrm{Mo}_{2} \mathrm{O}_{9}$ series, fitted with a conventional Arrhenius law in the linear part at low temperature (dashed black lines) and with a VTF model when departure from linearity is observed at higher temperature (solid black lines). At the bottom of each graph, plot of the first derivative of the conduction with respect to temperature is shown. The conductivity curve of $\mathrm{La}_{2} \mathrm{Mo}_{2} \mathrm{O}_{9}$ is added as solid red line for reference.

Table 3. Average Thermal Expansion Coefficients of $\mathrm{La}_{2-x} \mathrm{Eu}_{x} \mathrm{Mo}_{2} \mathrm{O}_{9}$ Samples Determined by Temperature-Controlled X-ray Powder Diffraction

\begin{tabular}{lrc}
\hline \multicolumn{1}{c}{$x$} & $\begin{array}{r}\text { temperature } \\
\text { range }\left({ }^{\circ} \mathrm{C}\right)\end{array}$ & $\alpha\left(\times 10^{-6}{ }^{\circ} \mathrm{C}^{-1}\right)$ \\
\hline 0 & $\mathrm{RT}-580$ & 15.7 \\
& $580-1000$ & 20.1 \\
0.1 & $\mathrm{RT}-580$ & 16.0 \\
& $580-1000$ & 19.2 \\
0.15 & $570-1000$ & 20.6 \\
0.2 & $\mathrm{RT}-410$ & 16.5 \\
& $570-1000$ & 20.5 \\
0.25 & $\mathrm{RT}-420$ & 16.0 \\
0.3 & $\mathrm{RT}-420$ & 15.7 \\
0.4 & $\mathrm{RT}-420$ & 16.0
\end{tabular}

of a cubic member, whereas DTA thermogram clearly shows an endothermic peaks attributed to the $\alpha \rightarrow \beta$ phase transition. An attempt to explain these contradictory results will be given in Section 3.3.3.

$\mathrm{La}_{2-x} \mathrm{Eu}_{\mathbf{x}} \mathrm{Mo}_{2} \mathrm{O}_{9}$ with $0.25 \leq \boldsymbol{x} \leq \mathbf{0 . 4}$. As shown by room-temperature diffraction, the last three members of this series have a cubic symmetry. The thermal behavior of these compositions is similar to that previously shown for cubic members of the LAMOX family. ${ }^{7,17}$ Cell volume

(17) Georges, S.; Goutenoire, F.; Bohnké, O.; Steil, M. C.; Skinner, S. J.; Weimhöfer, H. D.; Lacorre, P. J. New. Mater. Electrochem. Syst. 2004, 7,51 . evolutions (Figure 5) and relative thermal expansions $\Delta l / l_{0}$ (Figure S3) present a departure from linearity above 400$450{ }^{\circ} \mathrm{C}$. However, the values of the thermal expansion coefficients (TEC) (Table 3), calculated in the linear part of the cell volume evolution, remain almost constant and comparable to that of $\alpha-\mathrm{La}_{2} \mathrm{Mo}_{2} \mathrm{O}_{9}$. It is worth noting that by DT analysis performed on all cubic samples (see the experimental conditions), a wide endothermic event around $450{ }^{\circ} \mathrm{C}$ (onset point) is detected upon heating, whereas a diffuse bump is noted during cooling (Figure 8). No evolution of these thermal events were noted when two additional cycles of heating-cooling were performed. In the same way, a deviation from a pure Arrhenius-type behavior, below $1000 / \mathrm{T} \approx 1.35 \mathrm{~K}^{-1}$, is noted on conductivity curves regardless of the value of $x$ (Figure 6).

This change in the conduction mechanism has been interpreted as resulting from a transition toward a VogelTammann-Fulcher (VTF) regime. ${ }^{17-18}$ Recently, a mathematical analysis ${ }^{7}$ of the flexibility of the anti-polyhedral framework ${ }^{5}$ of the $\beta-\mathrm{La}_{2} \mathrm{Mo}_{2} \mathrm{O}_{9}$ crystal structure was undertaken. The extra thermal volume expansion, observed above $450{ }^{\circ} \mathrm{C}$, was interpreted as originating from the opening up

(18) (a) Vogel, H. Phys. Z. 1921, 22, 645. (b) Tammann, V. G.; Hesse, H. Z. Anorg. Allg. Chem. 1926, 156, 245. (c) Fulcher, G. S. J. Am. Ceram. Soc. 1925, 8, 339 . 

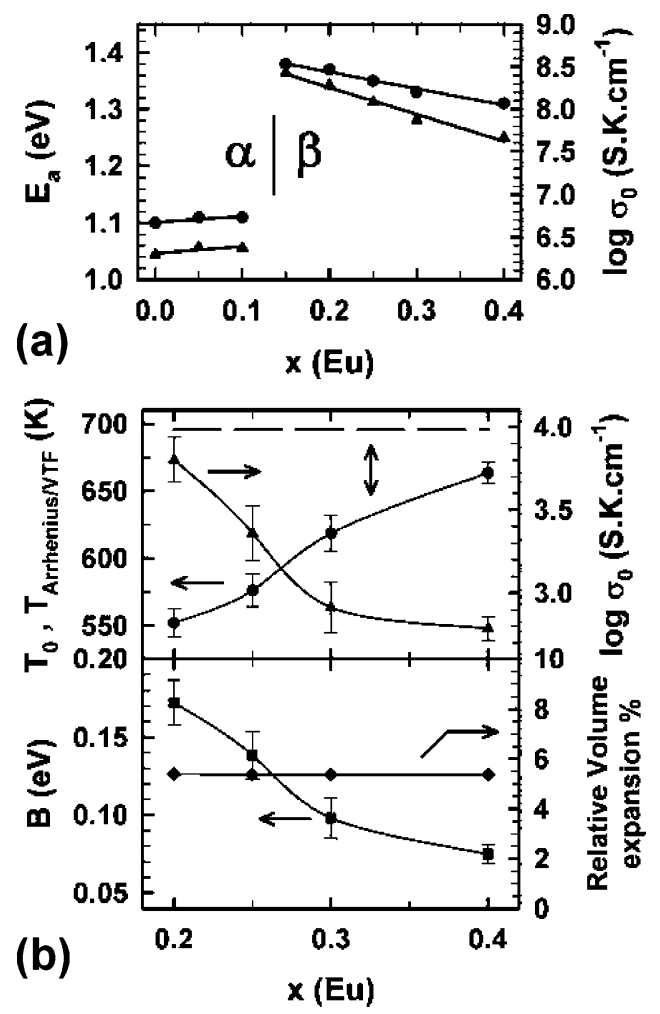

Figure 7. Evolution with europium content $x$ of (a) activation energy $E_{\mathrm{a}}$ (points) and pre-exponential factor $\sigma_{0}$ (triangles) of the Arrhenius law determined in the temperature range of $300-500{ }^{\circ} \mathrm{C}$ for $0 \leq x \leq 0.1$ and in the temperature range of $300-425{ }^{\circ} \mathrm{C}$ for $x \geq 0.15$ and (b) of the VTF parameters and the relative volume expansion $\left[V_{9500^{\circ} \mathrm{C}}-V_{25^{\circ} \mathrm{C}}\right] / V_{25^{\circ} \mathrm{C} \text {. The }}$ constant Arrhenius/VTF transition temperature (from DTA signal, conductivity curves, and thermal expansion) is added as a dashed line.

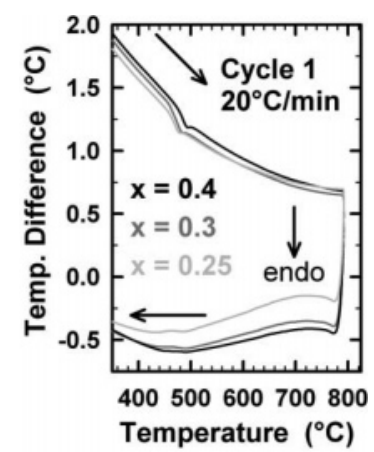

Figure 8. DTA thermograms of $\beta-\mathrm{La}_{2}{ }_{x} \mathrm{Eu}_{x} \mathrm{Mo}_{2} \mathrm{O}_{9}$ raw powder samples.

of tunnels through cooperative rotations of anti-tetrahedra [O1La 3 Mo]. Since mobile $\mathrm{O} 2$ and $\mathrm{O} 3$ oxide ions are located in these tunnels, the ionic migration would then be thermally assisted by the host matrix distortion/libration.

As shown in Figure 6, total conductivity was fitted with a conventional Arrhenius law in the linear part at low temperature and with the empirical Vogel-TammannFulcher (VTF) model when departure from linearity is observed at higher temperature. The VTF equation

$$
\sigma T=\sigma_{0} \exp \left(-B / R\left(T-T_{0}\right)\right)
$$

has three adjustable parameters: $\sigma_{0}$ is the pre-exponential factor, $B$ a pseudoactivation energy, and $T_{0}$ the temperature at which oxide ion disordering becomes dynamic. Values of the Arrhenius and of VTF parameters for all compositions are presented in Figure 7.

In the Arrhenius-type regime, the values of the activation energy $E_{\mathrm{a}}$ and of the pre-exponential factor $\sigma_{0}$ for $\beta$ - $\mathrm{La}_{2-x^{-}}$ $\mathrm{Eu}_{x} \mathrm{Mo}_{2} \mathrm{O}_{9}(x=0.15-0.4)$ samples are much larger than values obtained for $\alpha-\mathrm{La}_{2-x} \mathrm{Eu}_{x} \mathrm{Mo}_{2} \mathrm{O}_{9}(x=0,0.05,0.1)$ samples. Above $x=0.15, E_{\mathrm{a}}$ and $\sigma_{0}$ decrease linearly when the europium concentration increases. This significant increase of $\sigma_{0}$ between the $\alpha$ - and $\beta$-type phases could reflect that, in the latter, the diffusion of defects (vacancy migration entropy) and the concentration of defects allowing a hopping of mobile species is larger than in the vacancy ordered $\alpha$-phase.

In the high-temperature regime (VTF), an increase of the temperature $T_{0}$ and a decrease of $\sigma_{0}$ and $B$ with increasing $x$ (taking into account the $x=0.2$ composition described in the next paragraph) are observed, both followed by a kind of leveling off above $x=0.3$ (Figure 7). Note, that the pseudoactivation energy we find for $x=0.4$ is comparable to values determined for crystallized fast silver ion conductors $\mathrm{Ag}_{7} \mathrm{GeS}_{5} \mathrm{I}(0.06 \mathrm{eV})$ and $\alpha-\mathrm{AgI}(0.06 \mathrm{eV}) .{ }^{19}$

One possible explanation of the evolution of $T_{0}$ is that oxygen vacancies $\square$ present intrinsically in $\beta-\mathrm{La}_{2} \mathrm{Mo}_{2} \mathrm{O}_{9} \square$ (LPS concept $)^{20}$ could be trapped around substituting cations. The average coordination of lanthanum ions determined from the partial occupancy of $\mathrm{O} 2$ and $\mathrm{O} 3$ sites in the $\beta$-form is 10. This oxygen vacancies/Eu $\mathrm{u}^{3+}$ ions association is plausible since the trivalent europium cation, smaller in size than lanthanum, adopts generally surroundings with lower coordinence number. In crystal structures of europium molybdates, the rare earth ion is eight-fold coordinated within a distorted square antiprism. ${ }^{21}$ For reference, lanthanum is nineor ten-fold coordinated in the structures of $\alpha-$ and $\beta$ - $\mathrm{La}_{2}-$ $\mathrm{Mo}_{4} \mathrm{O}_{15}{ }^{22}$ In our analysis of the VTF behavior, we consider that $T_{0}$ is the transition temperature from a static to dynamic disordered states of oxide ions. Thereby, an increase of the number of vacancies trapped as the amount of europium increases could explain that the transition toward a dynamic disordered state occurs at higher temperature. However, the range of lanthanum substitution investigated here is rather limited. As a matter of fact, this oxygen vacancies/ $\mathrm{Eu}^{3+}$ ions association might be small and is consistent with the weak incidence on ionic conductivity noted. But, it is amazing that a 0.2 variation of the europium content induces a shift of $T_{0}$ larger than $100 \mathrm{~K}$. It must be noted that, whatever the value of $x$, the departure from linearity (Arrhenius/VTF transition) starts at around $695 \mathrm{~K}$. As shown in Figure 7, a substantial decrease of the difference between $T_{\text {Arr } / \mathrm{VTF}}$ and $T_{0}$ occurs upon substitution.

In the assumption of mobility assisted by the libration of the matrix, a question can be raised: do the relative volume expansion and the VTF parameters $\sigma_{0}$ and $B$ have an identical

(19) Ribes, M.; Taillades, G.; Pradel, A. Solid State Ionics 1998, 105, 159.

(20) Lacorre, P. Solid State Sci. 2000, 2, 755.

(21) (a) Naruke, H.; Yamase, T. Inorg. Chem. 2002, 41, 6514. (b) Naruke, H.; Yamase, T. J. Solid State Chem. 2001, 161, 85.

(22) (a) Dubois, F.; Goutenoire, F.; Laligant, Y.; Suard, E.; Lacorre, P. J. Solid State Chem. 2001, 159, 228. (b) Naruke, H.; Yamase, T. J. Solid State Chem. 2003, 173, 407. 
composition dependence? A conduction activation energy is the sum of the strain energy required to dilate or distort the network to allow a mobile ion to hop from one site to another and the energy binding an ion to one equilibrium site (related to the bond dissociation energy). As shown in Figure 7 , the relative volume expansion $\left[V_{950^{\circ} \mathrm{C}}-V_{25^{\circ} \mathrm{C}}\right] /$ $V_{25^{\circ} \mathrm{C}}$ (or \% unoccupied volume $=\left[V_{25^{\circ} \mathrm{C}}-V_{\text {ions }} / V_{25^{\circ} \mathrm{C}}\right.$ ) of cubic Eu members is constant regardless of the europium fraction. Because the expansion of the host matrix behaves the same way, despite the reduction of the unit cell volume as the europium content increases (Figure 5), the strain energy might not change within the series. The average bond energy of mobile anion is dependent on its cationic neighborhood. It is worthy to note that the strength of $\mathrm{Eu}-\mathrm{O}$ bond $(479(10) \mathrm{kJ} / \mathrm{mol})^{23}$ is smaller than the strength of $\mathrm{La}-\mathrm{O}$ bond $(799(4) \mathrm{kJ} / \mathrm{mol}) .^{23}$ It gives an explanation of the evolution of the pseudoactivation energy with the substitution level since the higher the europium content, the lower the average bond energy, and the easier the diffusion of oxide ions. However, the ionic conductivity did not reflect this trend. To understand, let us analyze the evolution of $\sigma_{0}$. Because the pre-exponential factor $\sigma_{0}$ is proportional to the concentration of defects allowing a hopping of mobile species, the continuous decrease of this concentration as increasing the europium content up to $x=0.3$ could be ascribed to the progressive trapping of oxygen vacancies around $\mathrm{Eu}^{3+}$ ions assumed previously. Note, that the magnitude of the variation of $\sigma_{0}$ is similar to that found in the Arrhenius-type regime. The kind of leveling off above $x=0.3$ would mean that a maximum of oxygen vacancies and $\mathrm{Eu}^{3+}$ ions associated is probably reached for the $x=0.4$ sample. Thereby, the europium substitution has two antagonistic effects: it lowers the activation energy but favors the trapping of oxygen vacancies.

Metastability and Sample Shaping: The Case of $\mathbf{L a}_{1.85} \mathbf{E u}_{0.15} \mathbf{M o}_{2} \mathrm{O}_{9}$ and $\mathbf{L a}_{1.8} \mathbf{E u}_{0.2} \mathbf{M o}_{2} \mathbf{O}_{9}$. In section 3.1, room-temperature diffraction and DT analysis have shown that the $x=0.15$ and 0.2 compositions stand apart from the others. Indeed, the two polymorphs $(\alpha+\beta)$ coexist at ambient temperature for $\mathrm{La}_{1.85} \mathrm{Eu}_{0.15} \mathrm{Mo}_{2} \mathrm{O}_{9}$. It was also supposed that the RT $\beta$-phase obtained for both samples was not the most stable form. This narrow substitution range $(0.1<x<0.25)$ probably forms a border region between single monoclinic phase and cubic phase existence domains. A deeper insight of the system was achieved thanks to temperature-controlled X-ray powder diffraction. These measurements, performed on raw powder samples, revealed a series of structural transitions upon heating (Figure 5). The insets in Figure 5 show the evolution of the pseudocubic (231) reflection with increasing temperature.

At first, let us focus on $\mathrm{La}_{1.8} \mathrm{Eu}_{0.2} \mathrm{Mo}_{2} \mathrm{O}_{9}$. Upon heating, the raw powder sample exhibits a complete conversion to monoclinic $\alpha$-form in a limited thermal range, $\sim 450-$ $560{ }^{\circ} \mathrm{C}$, before undergoing the $\alpha / \beta$ transition, like in pure

(23) Kerr, J. A. In CRC Handbook of Chemistry and Physics 1998-1999: A Ready-Reference Book of Chemical and Physical Data, 79th ed.; Lide, D. R., Ed.; CRC Press: Boca Raton, FL, 1998.
$\mathrm{La}_{2} \mathrm{Mo}_{2} \mathrm{O}_{9}$. The single cell volume relative to the transient $\alpha$-phase is found to be slightly smaller than the one of the $\beta$-phase before the inverse $\beta / \alpha$ transition. These doublereversed transitions indicate that the initial $\beta$-phase, when the powder sample is cooled from $1000{ }^{\circ} \mathrm{C}$ at $5{ }^{\circ} \mathrm{C} / \mathrm{min}$ (sample 1), is metastable in nature. According to Turnbull, ${ }^{24}$ metastability may be: (1) morphological when it arises from a decrease of the particule size (nanocrystalline anatase), ${ }^{24}$ (2) topological when it arises from an increase of disorder leading to alternate crystalline or amorphous phases, or (3) compositional when it arises from an increase of solute trapping leading to extended solid solution.

Here, the metastability is topological since the metastable $\beta$-form is a disordered version of the room-temperature stable $\alpha$-phase. In such a case, the slower the cooling rate, the smaller the proportion of metastable $\beta$-form. To highlight this behavior, sample 2 has been prepared starting from sample 1 annealed at $500{ }^{\circ} \mathrm{C}$ for $12 \mathrm{~h}$ (heating rate $5{ }^{\circ} \mathrm{C} /$ min) and cooled slowly at $0.5^{\circ} \mathrm{C} / \mathrm{min}$. Figure $\mathrm{S} 4$ displays the room-temperature X-ray powder diffraction pattern of sample 2. One can notice that the stabilization of the monoclinic $\alpha$-form at room temperature occurred since all diffraction lines are broadened and superstructure peaks at low $2 \theta$ scattering angle appeared. Single monoclinic subcell parameters $a=7.1356(1) \AA, b=7.1434(1) \AA, c=7.1444$ (1) $\AA, \beta=89.733(1)^{\circ}$, and $V=364.16(1) \AA{ }^{3}$ determined from Le Bail's fit disclose the weak distortion of the structure, while retaining the cell volume almost constant after the transformation (See Figure 4). A diffraction study of the thermal evolution of the (231) line was carried out upon heating up to $950{ }^{\circ} \mathrm{C}$ (Figure 5). Powder of sample 2 behaves the same way as $\mathrm{La}_{2} \mathrm{Mo}_{2} \mathrm{O}_{9}$ with the occurrence of the first-order transition around $580{ }^{\circ} \mathrm{C}$ (Figure S4).

At this stage, it seems clear that a competitive phase selection problem takes place in $\mathrm{La}_{1.85} \mathrm{Eu}_{0.15} \mathrm{Mo}_{2} \mathrm{O}_{9}$ because the two polymorphs $(\alpha+$ metastable $\beta)$ coexist at room temperature. The crystallization kinetics for the monoclinic and cubic phases are all the more competitive than these phases are oxygen/vacancy ordered and disordered versions of the same structure. Figure 5 shows that a smooth curvature of the cell volume expansion is noted below $400{ }^{\circ} \mathrm{C}$ for this sample, whereas the thermal expansion was linear in this temperature range for the europium-richer composition $x=$ 0.2 . Then, in the thermal range of $\sim 450-560{ }^{\circ} \mathrm{C}$ (in red color in Figure 5), $\mathrm{La}_{1.85} \mathrm{Eu}_{0.15} \mathrm{Mo}_{2} \mathrm{O}_{9}$ has a monoclinic symmetry, as previously observed for $\mathrm{La}_{1.8} \mathrm{Eu}_{0.2} \mathrm{Mo}_{2} \mathrm{O}_{9}$. The continuous decrease of the slope, upon heating to $450{ }^{\circ} \mathrm{C}$, for $\mathrm{La}_{1.85} \mathrm{Eu}_{0.15} \mathrm{Mo}_{2} \mathrm{O}_{9}$ could reflect a progressive conversion of the metastable $\beta$-phase into $\alpha$-form with a slightly smaller cell volume. Note, that the conversion taking place at $450{ }^{\circ} \mathrm{C}$ for $\mathrm{La}_{1.8} \mathrm{Eu}_{0.2} \mathrm{Mo}_{2} \mathrm{O}_{9}$ is sudden. Hayward et al. ${ }^{25}$ have shown that a continuous evolution of the cell parameter $a$ across the transition can be observed for $\mathrm{La}_{2} \mathrm{Mo}_{2} \mathrm{O}_{9}$ when a powder sample is quenched from high temperature above

(24) (a) Turnbull, D. Metall. Trans. A 1981, 12 (5), 695. (b) Zhang, H.; Banfield, J. F. J. Mater. Chem. 1998, 8 (9), 2073.

(25) Hayward, S. A.; Redfern, S. A. T. J. Phys.: Condens. Matter. 2004, 16,3571 . 

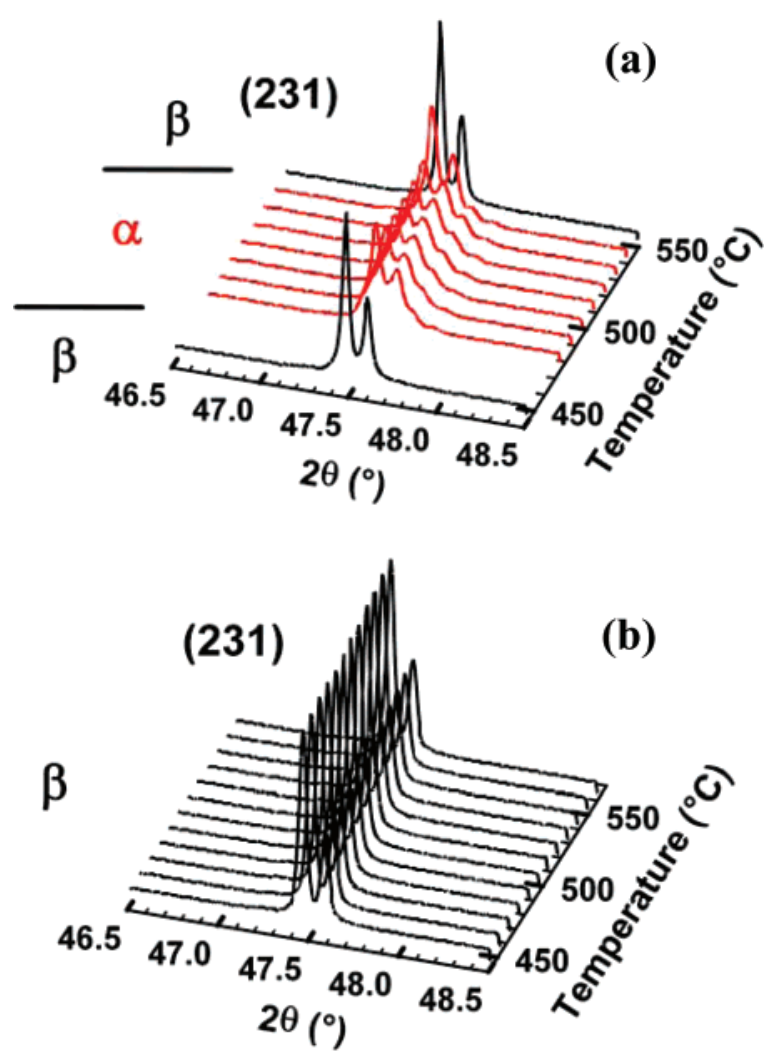

Figure 9. Thermal evolution of the (231) diffraction line of dense pellet samples of $\mathrm{La}_{1.85} \mathrm{Eu}_{0.15} \mathrm{Mo}_{2} \mathrm{O}_{9}$ (a) and $\mathrm{La}_{1.8} \mathrm{Eu}_{0.2} \mathrm{Mo}_{2} \mathrm{O}_{9}$ (b) upon heating.

$580^{\circ} \mathrm{C}$. In such a situation, the transition is thermodynamically second order.

The electrical property of the $x=0.15$ and 0.2 compositions was measured from pellets prepared with powders cooled down at $5{ }^{\circ} \mathrm{C} / \mathrm{min}$. The evolution of the conductivity with temperature is reported in Figure 6. Contrary to all expectations, the curve of $\mathrm{La}_{1.8} \mathrm{Eu}_{0.2} \mathrm{Mo}_{2} \mathrm{O}_{9}$ did not show any thermal instability and looks like the curve of a cubic member. In contrast, the successive transitions highlighted by temperature-controlled X-ray diffraction on $\mathrm{La}_{1.85} \mathrm{Eu}_{0.15^{-}}$ $\mathrm{Mo}_{2} \mathrm{O}_{9}$ powder sample remain present in the temperature dependence of conductivity. To elucidate this singular difference, the evolution of the (231) diffraction line upon heating to $950{ }^{\circ} \mathrm{C}$ was recorded on both samples, shaped as a pellet. Large pellets $(13 \mathrm{~mm}$ in diameter and $0.8 \mathrm{~mm}$ in thickness) were prepared starting from ball-milled powder and sintered in the conditions determined previously. The diffractograms are displayed in Figure 9. Diffraction revealed that only the $x=0.2$ sample is sensitive to sample shaping because the cubic $\beta$-phase is henceforth stable in the whole temperature range explored. These results are in perfect agreement with conductivity measurements.

This metastable behavior and the stabilization of the cubic $\beta$-form through sample shaping as a pellet was recently evidenced in the aliovalent substituted lanthanum molybdate $\mathrm{La}_{1.92} \mathrm{Ca}_{0.08} \mathrm{Mo}_{2} \mathrm{O}_{8.96}{ }^{26}$ At first, one could have speculated that this metastability arises from the change of oxygen/ vacancy balance through calcium substitution in $\mathrm{La}_{2} \mathrm{Mo}_{2} \mathrm{O}_{9}$.

(26) Selmi, A.; Corbel, G.; Lacorre, P. Solid State Ionics 2006, 177, 3051.

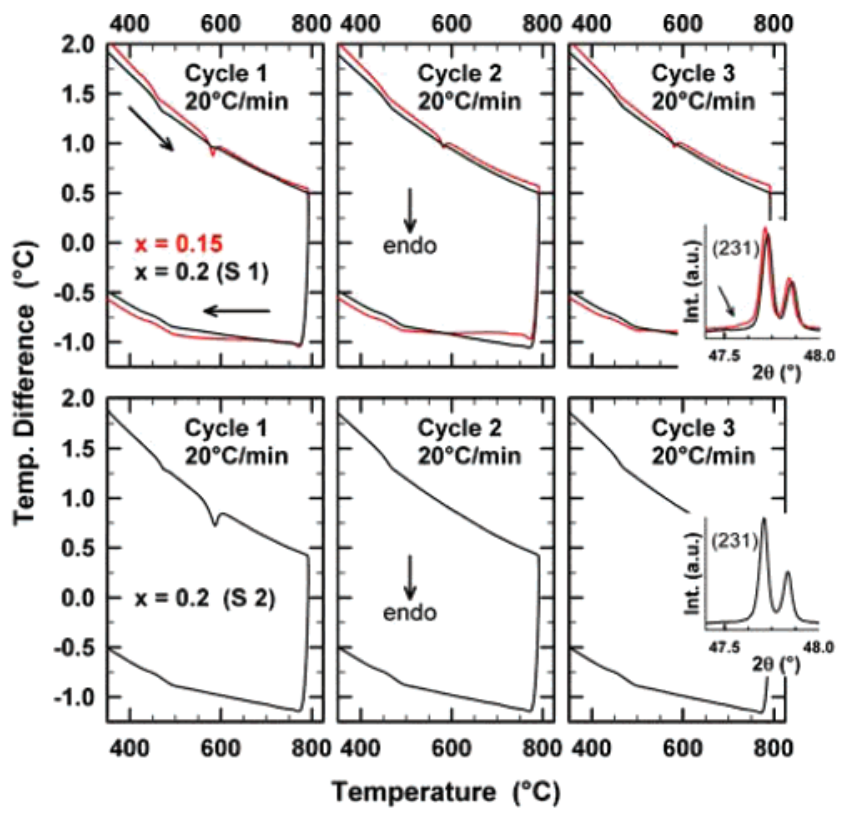

Figure 10. Consecutive DTA measurements during repeated thermal cycles (3 loops of heating at $800{ }^{\circ} \mathrm{C}$ and cooling to $160{ }^{\circ} \mathrm{C}$, rate of $20{ }^{\circ} \mathrm{C} / \mathrm{min}$ ) performed on powder samples of $\mathrm{La}_{1.85} \mathrm{Eu}_{0.15} \mathrm{Mo}_{2} \mathrm{O}_{9}$ (red line) and $\mathrm{La}_{1.8} \mathrm{Eu}_{0.2} \mathrm{Mo}_{2} \mathrm{O}_{9}$ (black lines, samples 1 and 2). The insets show the (231) cubic diffraction line recorded after the cycle 3. For arrow, see text.

This work demonstrates that such a behavior can also be encountered in an isovalent substituted molybdate $\mathrm{La}_{1.8} \mathrm{Eu}_{0.2^{-}}$ $\mathrm{Mo}_{2} \mathrm{O}_{9}$. However, a difference exists with $\mathrm{La}_{1.92} \mathrm{Ca}_{0.08}$ $\mathrm{Mo}_{2} \mathrm{O}_{8.96}$ because, in this last composition, a substitute depletion/recombination process occurs above $640{ }^{\circ} \mathrm{C}$, which is not observed here.

In the light of what we observed for $\mathrm{La}_{1.8} \mathrm{Eu}_{0.2} \mathrm{Mo}_{2} \mathrm{O}_{9}$, a way to explain the Marrero-López et al. conduction measurement performed on nanocrystalline $\alpha-\mathrm{La}_{1.9} \mathrm{Eu}_{0.1} \mathrm{Mo}_{2} \mathrm{O}_{9}(\approx 30$ $\mathrm{nm})$ is to consider that the phase stability of Eu-substituted compounds is also sensitive on grain size. As a matter of fact, the compositional range where metastability takes place for our samples would be extended to lower europium content when the samples are elaborated from freeze-dried precursors. This assumption would explain the coexistence of $\alpha$ - and $\beta$-phases that Marrero-López et al. observed in an extended range of composition $0.1 \leq x<0.25$. The metastability would also be morphological. ${ }^{24}$

Metastability and Arrhenius/VTF Transition. The effect of repeated thermal cycles on the phase stability of $\mathrm{La}_{1.85} \mathrm{Eu}_{0.15} \mathrm{Mo}_{2} \mathrm{O}_{9}$ and $\mathrm{La}_{1.8} \mathrm{Eu}_{0.2} \mathrm{Mo}_{2} \mathrm{O}_{9}$ (previous samples 1 and 2) was then investigated by DT analysis. Three cycles of heating/cooling at a rate of $20^{\circ} \mathrm{C} / \mathrm{min}$ were performed on $\sim 50 \mathrm{mg}$ of powder. All DTA thermograms of the $x=$ 0.15 analogue exhibit, upon heating, the sequence of phase transitions previously observed (Figure 10). However, a widening of the endothermic event around $580{ }^{\circ} \mathrm{C}$ occurs between the two first cycles. This signal remains unchanged during cycle 3 . This broadening, induced by the first rapid cooling, suggests that the fraction of coexisting phases ( $\alpha$ $+\beta$ metastable) changes before reaching an equilibrium after cycle 2 . This is the reason why the successive $\beta$ metastable $\rightarrow \alpha \rightarrow \beta$ phase transition remains present during the cycle 3 (Figure 10). The higher the cooling rate, the larger the 
proportion of $\beta$ metastable form. A comparison between diffraction pattern of the (231) line collected before DTA measurement (Figure 2) and after the last cycle (Figure 10) shows that the weaker peak at lower scattering angle (arrow in inset) becomes very diffuse. This is consistent with a slight decrease of the amount of the monoclinic phase.

For sample 1 of $\mathrm{La}_{1.8} \mathrm{Eu}_{0.2} \mathrm{Mo}_{2} \mathrm{O}_{9}$ (Figure 10), the amount of the monoclinic phase is suspected to be lower than the amount present in $\mathrm{La}_{1.85} \mathrm{Eu}_{0.15} \mathrm{Mo}_{2} \mathrm{O}_{9}$. The second peak at around $580{ }^{\circ} \mathrm{C}$ has completely disappeared after the first cooling at $20^{\circ} \mathrm{C} / \mathrm{min}$. This illustrates the decreasing tendency of the $\beta$ metastable disordered phase to order with increasing cooling rate. DTA thermograms recorded during cycles 2 and 3 look like the curve of a cubic europium substituted samples with the Arrhenius/VTF transition at around 450 ${ }^{\circ} \mathrm{C}$ (Figure 8 and 10). Bearing in mind that a monoclinic symmetry at room temperature was identified on the powder diffraction pattern collected on the slowly cooled sample 2, the reminiscence of $\beta$-metastable/ $\alpha$ transition upon the first heating up at $20{ }^{\circ} \mathrm{C} / \mathrm{min}$ is surprising. It shows that the cooling rate of $0.5^{\circ} \mathrm{C} / \mathrm{min}$ used to prepare sample 2 is not slow enough to obtain a pure $\alpha$-type phase at room temperature. A part of the $\beta$-metastable phase is retained in quantity too weak to be detected by powder diffraction (Figure S4). The two thermograms recorded during the next cycles 2 and 3 are similar to the curves of sample 1. The conversion into a single cubic phase seems to be effective as soon as the first rapid cooling down is performed.

\section{Conclusion}

In this paper, the solid solution $\mathrm{La}_{2-} \mathrm{Eu}_{x} \mathrm{Mo}_{2} \mathrm{O}_{9}$ was reexamined to obtain a deeper insight into the influence of trivalent europium on the crystal structure, thermal stability, and electrical properties. As mentioned by Lubomirsky, ${ }^{27}$ collective effects induced by interacting point defects occur in fast ion conductor because the concentration of point defects is very high. When a partial substitution is performed in a solid such as $\mathrm{La}_{2} \mathrm{Mo}_{2} \mathrm{O}_{9}$, the equilibrium of point defects is naturally affected in a different manner depending on the substitution level. Below an europium content of $x=0.1$, the interaction of point defects (substitute/oxygen vacancies) leads to an order-disorder transition $(\alpha \rightarrow \beta)$ associated with a sudden volume expansion (spontaneous strain). However, this study reveals that the situation could be more complex when the europium increases up to $x=0.2$, since the enthalpy of such a transition is greatly lowered by the random cationic substitution (see for instance DT thermograms).

(27) Lubomirsky, I. Solid State Ionics 2006, 177, 1639.
Thereby, many factors as the thermal history (temperature, heating and cooling rates), the external stress (pressure), and the internal strain induced by sample shaping change the equilibrium of point defects. Indeed when a cooling rate of $5{ }^{\circ} \mathrm{C} / \mathrm{min}$ is used for the preparation of $\mathrm{La}_{1.85} \mathrm{Eu}_{0.15} \mathrm{Mo}_{2} \mathrm{O}_{9}$ and $\mathrm{La}_{1.8} \mathrm{Eu}_{0.2} \mathrm{Mo}_{2} \mathrm{O}_{9}$ samples, the low temperature $\alpha$-form and a pseudo- $\beta$-form can coexist at room temperature while preserving a homogeneous europium distribution within the sample. The stress induced by cooling allows the existence of a pseudo- $\beta$-form with a $2 \mathrm{D}$ disordering of the oxygen sublattice (TEM study), intermediate situation between the complex ordering in the $\alpha$-phase, and 3D disordering in the $\beta$-phase. A relaxation of the system occurs upon heating leading to a release of topological metastability (successive $\beta / \alpha / \beta$ phase transitions). The decrease of the enthalpies associated to the (metastable $\beta$ ) $/ \alpha$ and $\alpha / \beta$ transitions with increasing the europium content up to $x=0.2$ makes the permanent stabilization of the $\beta$ phase possible, thanks to mechanical constraints such as sample shaping.

Above an europium content of $x=0.2$, increasing the substitution rate favors the interactions of points defects (substitute/oxygen vacancies). As pointed out by Greenberg et al., ${ }^{28}$ the development of such a chemical strain effect could be accompanied by a large change in specific volume. In $\mathrm{Bi}_{2} \mathrm{O}_{3}$-based oxide ion conductors, ${ }^{29}$ the clear increase of thermal expansion coefficient around $500{ }^{\circ} \mathrm{C}$ is ascribed to the disordering of oxide ions at high temperature. The extra volume expansion measured above $450{ }^{\circ} \mathrm{C}$, which characterizes all cubic LAMOX members, could also be seen as a clear manifestation of this phenomenon. However, the pronounced curvature of the thermal volume expansion and of the conductivity thermal evolution would indicate that the reaction of defect association/dissociation upon heating is complex. This is the reason why, upon substitution, the trapping of oxygen vacancies around europium cannot decrease significantly the anionic conductivity because a lowering of the average bond energy occurs in parallel.

Supporting Information Available: Europium valence determination, representative photos of $\mathrm{La}_{2} \mathrm{Mo}_{2} \mathrm{O}_{9}$ and $\mathrm{La}_{2-x} \mathrm{Eu}_{x} \mathrm{Mo}_{2} \mathrm{O}_{9}$, plots of $\Delta l / l_{0}$ as a function of temperature, and stabilization of $\alpha-\mathrm{La}_{1.8} \mathrm{Eu}_{0.2} \mathrm{Mo}_{2} \mathrm{O}_{9}$ at room temperature.

(28) Greenberg, M.; Wachtel, E.; Lubomirsky, I.; Fleig, J.; Maier, J. Adv. Funct. Mater. 2006, 16, 48

(29) (a) Naumovich, E. N.; Kharton, V. V.; Samokhval, V. V.; Kovalevsky, A. V. Solid State Ionics 1997, 93, 95. (b) Kharton, V. V.; Naumovich, E. N.; Yaremchenko, A. A.; Marques, F. M. B. J. Solid State Electrochem. 2001, 5, 160. (c) Wang, X.-P.; Corbel, G.; Fang, Q.-F.; Lacorre, P. J. Mater. Chem. 2006, 16, 1561. 